\title{
Carbon Dioxide-Related Changes in Cerebral Blood Volume and Cerebral Blood Flow in Mechanically Ventilated Preterm Neonates: Comparison of Near Infrared Spectrophotometry and ${ }^{133}$ Xenon Clearance
}

\author{
O. PRYDS, G. GREISEN, L. L. SKOV, AND B. FRIIS-HANSEN \\ Department of Neonatology, State University Hospital (Rigshospitalet), Copenhagen, Denmark
}

\begin{abstract}
Carbon dioxide-induced changes in near infrared spectrophotometry recordings were compared with changes in cerebral blood flow estimated by ${ }^{133}$ Xenon clearance (global cerebral blood flow (infinity)) at serial measurements in $\mathbf{2 4}$ mechanically ventilated preterm infants (mean gestational age $30.2 \mathrm{wk}$ ). In all infants, three measurements were taken at different arterial carbon dioxide tension levels (mean $4.4 \mathrm{kPa}$, range $2.1-7.8$ ) obtained by adjustment of the ventilator settings. Mean arterial blood pressure changed spontaneously, whereas arterial oxygen tension was kept within normal range. At all wavelengths $(904,845,805$, and $775 \mathrm{~nm})$, the OD increased at higher arterial carbon dioxide tension levels, indicating cerebral vasodilation. This conclusion was supported by conversion of the data to changes in oxygenated and deoxygenated $\mathrm{Hb}$ concentration. A parallel increase in cerebral blood volume index and global cerebral blood flow (infinity) was found $(p<0.0001)$. The oxygenation level of cytochrome $\mathrm{aa}_{3}$ increased with increases in oxygen delivery $(p<0.0001)$. This observation, however, may have been artifactual due to cross-talk between the oxidized cytochrome aa $a_{3}$ and the oxygenated $\mathrm{Hb}$ signals, as these signals were closely interrelated in the present experimental design. We suggest that near infrared spectrophotometry may be used for estimation of the cerebral blood volume index/cerebral blood flow- $\mathrm{CO}_{2}$ reactivity within a wide range of arterial carbon dioxide tension. Knowledge of the light path length would put this estimation on a quantitative basis. (Pediatr Res 27: 445-449, 1990)
\end{abstract}

\section{Abbreviations}

CBF, cerebral blood flow

$\mathrm{CBF}_{\infty}$, global cerebral blood flow (infinity)

$\mathrm{CBV}_{\mathrm{l}}$, cerebral blood volume index

HbC, blood hemoglobin concentration (tetraheme molecule)

$\mathrm{HbO}_{2}$, oxygenated hemoglobin

HbR, deoxygenated hemoglobin

HbTOT, total $\mathbf{H b}$

MABP, mean arterial blood pressure

NIRS, near infrared spectrophotometry

CI, confidence interval

$\mathrm{PaCO}_{2}$, arterial carbon dioxide tension

$\mathrm{PaO}_{2}$, arterial oxygen tension

$\mathrm{SaO}_{2}$, arterial blood oxygen saturation

Received March 15, 1989; accepted November 28, 1989

Correspondence: O. Pryds. Department of Neonatology, Rigshospitalet, Blegdamsvej, 2100 Copenhagen $\varnothing$, Denmark.
The method of NIRS has been proposed for noninvasive monitoring of changes in the amount of $\mathrm{HbO}_{2}$ and $\mathrm{HbR}$ in the brain as well as changes in the redox level of cytochrome $a_{3}$, the terminal member of the respiratory chain $(1-3)$. This technique may have a particular application for the evaluation of adequate oxygen delivery to the brain of sick preterm infants, to prevent hypoxic-ischemic encephalopathy.

No prior study has tried to validate the NIRS recordings in preterm infants by cerebral physiologic variables. Therefore, we investigated how changes in $C B V_{I}$ detected by NIRS were related to changes in CBF, and whether changes in saturation of brain $\mathrm{Hb}$ and redox level of cytochrome $\mathrm{aa}_{3}$, respectively, were related to changes in oxygen delivery to the brain.

Carbon dioxide-induced cerebral vasodilation results in a proportional increase in $\mathrm{CBV}$ and $\mathrm{CBF}$ in experimental animals over a wide range of $\mathrm{PaCO}_{2}$ (4-7). In human adults the CBV$\mathrm{CO}_{2}$ and $\mathrm{CBF}-\mathrm{CO}_{2}$ reactivities are 1:2 to $1: 4(8,9)$. Therefore, our study was designed to evaluate the effect of acute changes in $\mathrm{PaCO}_{2}$.

\section{MATERIALS AND METHODS}

NIRS. NIRS relies on the relative transparency of the neonate's head to near infrared light, which is attenuated by scattering and absorption in the tissues. The attenuation due to scattering may be assumed to be constant, whereas changes of absorbed light depend on changes in the chromophore concentrations ( $\mathrm{Hb}$ and cytochrome $\mathrm{aa}_{3}$ ) and the proportions of their oxygenated and deoxygenated forms. By selection of appropriate wavelengths, algorithms can be developed for the calculation of changes in $\mathrm{HbO}_{2}$ and $\mathrm{HbR}$ and oxidized cytochrome $\mathrm{aa}_{3}$, respectively (see below).

The NIRS instrument consists of four semiconductor laser diodes (class 3B) with wavelengths of $904,845,805$, and 775 nm. The lasers are operated sequentially, and pulsed with a repetition rate of $500 \mathrm{~Hz}$ for $200 \mathrm{~ns}$. Optical fiber bundles are used to transmit and receive the light. The energy emitted by each diode (peak power $10 \mathrm{~W}$, mean power $4 \mathrm{~mW}$ ) is several orders of magnitude below the safety limits (BS4803).

A digital computer calculates the amount of absorbed light within the head and displays the raw and converted data, respectively. The equipment was developed in Professor P. Rolfe's laboratories and made available by Radiometer (Copenhagen, Denmark).

To improve the signal to noise ratio in our study, the NIRS data were averaged over $30-$ s periods. From measurements on glass filters of $8 \mathrm{OD}$, a coefficient of variation of $0.01-0.04 \%$ over the 30 -s period was found. System drift was less than 0.004 $\mathrm{OD} / \mathrm{h}$ for all four laser diodes. 
Table 1. Relative changes (SEM) in $O D^{*}$ for the four wavelengths (nm) 904,845, 805, and 775 vs changes in $\mathrm{PaCO}_{2}$ and $C B F_{\infty}$, respectively $\dagger$

\begin{tabular}{llrrr}
\hline $\mathrm{PaCO}$ & \multicolumn{4}{c}{$\mathrm{OD}$} \\
$\mathrm{nm}$ & \multicolumn{1}{c}{ change $/ \mathrm{kPa}$} & $p$ & change $/ \mathrm{mL} / 100 \mathrm{~g} / \mathrm{min}$ & $p$ \\
\hline 904 & $0.00749(0.00108)$ & $<0.0001$ & $0.00259(0.00042)$ & $<0.0001$ \\
845 & $0.00766(0.00110)$ & $<0.0001$ & $0.00263(0.00044)$ & $<0.0001$ \\
805 & $0.00744(0.00119)$ & $<0.0001$ & $0.00268(0.00045)$ & $<0.0001$ \\
775 & $0.00350(0.0011)$ & 0.0018 & $0.00166(0.00035)$ & $<0.0001$ \\
\hline
\end{tabular}

* Regression coefficients.

$\dagger$ Results based on 72 investigations in 24 preterm neonates.

Table 2. Mean $\mathrm{CBF}_{1}-\mathrm{CO}_{2}$ and $\mathrm{CBF}_{\infty}-\mathrm{CO}_{2}$ reactivities (SEM) in 24 preterm infants*

\begin{tabular}{cccrcc}
\hline & \multicolumn{3}{c}{$\mathrm{CBV}_{1}-\mathrm{CO}_{2}(\mathrm{~mL} / 100 \mathrm{~g}$} & \multicolumn{3}{c}{$\begin{array}{c}\mathrm{CBF}_{\infty}-\mathrm{CO}_{2} \\
(\% / \mathrm{kPa})\end{array}$} & $p$ \\
\hline $\mathrm{Dge} 1$ & 13 & $1.46(0.42)$ & 0.0010 & $11.9(2.3)$ & 0.0002 \\
$\mathrm{D} 2$ & 11 & $2.06(0.52)$ & 0.0003 & $27.3(3.9)$ & $<0.0001$ \\
All & 24 & $1.70(0.33)$ & $<0.0001$ & $17.6(2.3)$ & $<0.0001$ \\
\hline
\end{tabular}

* Infants were grouped according to age at investigation.

Algorithm development. The method uses the known absorption properties of $\mathrm{Hb}$ and the cytochrome complex. In addition, the in vivo extinction coefficients of the three chromophores at each of the wavelengths must be known. A minimum of three wavelengths is necessary to solve an equation with three variables; we used 775,805 , and $904 \mathrm{~nm}$ for the conversion to concentrations.

At each of the wavelengths, the absorbance $(A)$ is proportional to the product of the extinction coefficient of the chromophore (e), the concentration of the chromophore (c), and the path length of the light (1). The total absorbance $\left(A_{n}\right)$ at one wavelength $(\mathrm{n})$ is the sum of the absorbances of the different absorbing components:

$$
A_{n}=e_{\mathrm{HbRn}} \times 1 \times \mathrm{c}_{\mathrm{HbR}}+\mathrm{e}_{\mathrm{HbO}_{2} \mathrm{n}} \times 1 \times \mathrm{c}_{\mathrm{HbO}_{2}}+\mathrm{e}_{\mathrm{Cytn}} \times 1 \times \mathrm{C}_{\mathrm{Cyt}}
$$

From the extinction coefficients provided by Wray et al. (10), the following multiplication factors were obtained by means of linear interpolation and matrix inversion:

\begin{tabular}{lrrr} 
& $775 \mathrm{~nm}$ & $805 \mathrm{~nm}$ & $904 \mathrm{~nm}$ \\
\cline { 2 - 4 } $\mathrm{HbO}_{2}$ & -0.944 & -0.126 & 1.441 \\
$\mathrm{HbR}$ & 1.554 & -0.739 & -0.382 \\
cytochrome $\mathrm{aa}_{3}$ & -0.095 & 0.378 & -0.213
\end{tabular}

Changes in concentrations of $\mathrm{HbO}_{2}, \mathrm{HbR}$, and cytochrome $\mathrm{aa}_{3}$ are calculated by summation of the absorption changes from the start of monitoring (measured as OD) multiplied by the above coefficients at each of the wavelengths. Changes in HbTOT are the sum of $\mathrm{HbO}_{2}$ and $\mathrm{HbR}$. Inasmuch as at present the path length is unknown, the results are relative and expressed with the unit $\mathrm{mM} \times$ path length in $\mathrm{cm}$.

$C B F$. CBF was determined by the i.v. ${ }^{133} \mathrm{Xe}$ technique, validated in preterm infants with respiratory distress (11). In short, $0.5-1.0 \mathrm{mCi} / \mathrm{kg}{ }^{133} \mathrm{Xe}$ was injected into a peripheral vein and the clearance recorded by scintillators placed over one frontoparietal region and the thorax, respectively. Fifteen min of recording time was used to improve the accuracy at low CBF levels (12). CBF was calculated from the time the activity in the lung had decreased to $15 \%$ of its peak activity, using the Obrist 2-compartment analysis modified to adjust for increased recirculation of tracer (12). $\mathrm{CBF}_{\infty}$ is the weighted mean of gray and white matter flow (12). The blood-brain partition coefficient was set to $0.8 \mathrm{~mL} / \mathrm{g}$ as previously calculated and adjusted for blood $\mathrm{Hb}$ (13). Inasmuch as the neonate's head is small and the scintillation geometry allows counting from a volume of $100-200 \mathrm{~mL}, \mathrm{CBF}_{\infty}$ is considered to represent global CBF and is expressed as $\mathrm{mL} /$ $100 \mathrm{~g} / \mathrm{min}$. Before each of the CBF measurements, the background activity was measured $(0.5$ or $5 \mathrm{~min})$ and taken into account in the subsequent $\mathrm{CBF}_{\infty}$ calculation.

Patients. Twenty-four preterm infants with a mean gestational age of $30.2 \mathrm{wk}$ (SD 2.8) and a mean birth wt of $1380 \mathrm{~g}$ (SD 504) were studied. Mean Apgar score at 5 min was 8.3 (SD 1.8) and mean umbilical cord $\mathrm{pH}$ was 7.27 (SD 0.16). None of the infants were hypoglycemic (blood glucose $<1.7 \mathrm{mM}$ ) at the time of the study. HbC was stable as no infant was transfused (mean tetraheme concentration $2.7 \mathrm{mM}$, SD 0.35 ).

Each study included three serial measurements within about $2 \mathrm{~h}$. Thirteen infants were investigated during the first day of life and another 11 infants during the second day. All infants were mechanically ventilated for respiratory distress and therefore routinely sedated with phenobarbital (loading dose $15 \mathrm{mg} / \mathrm{kg}$;

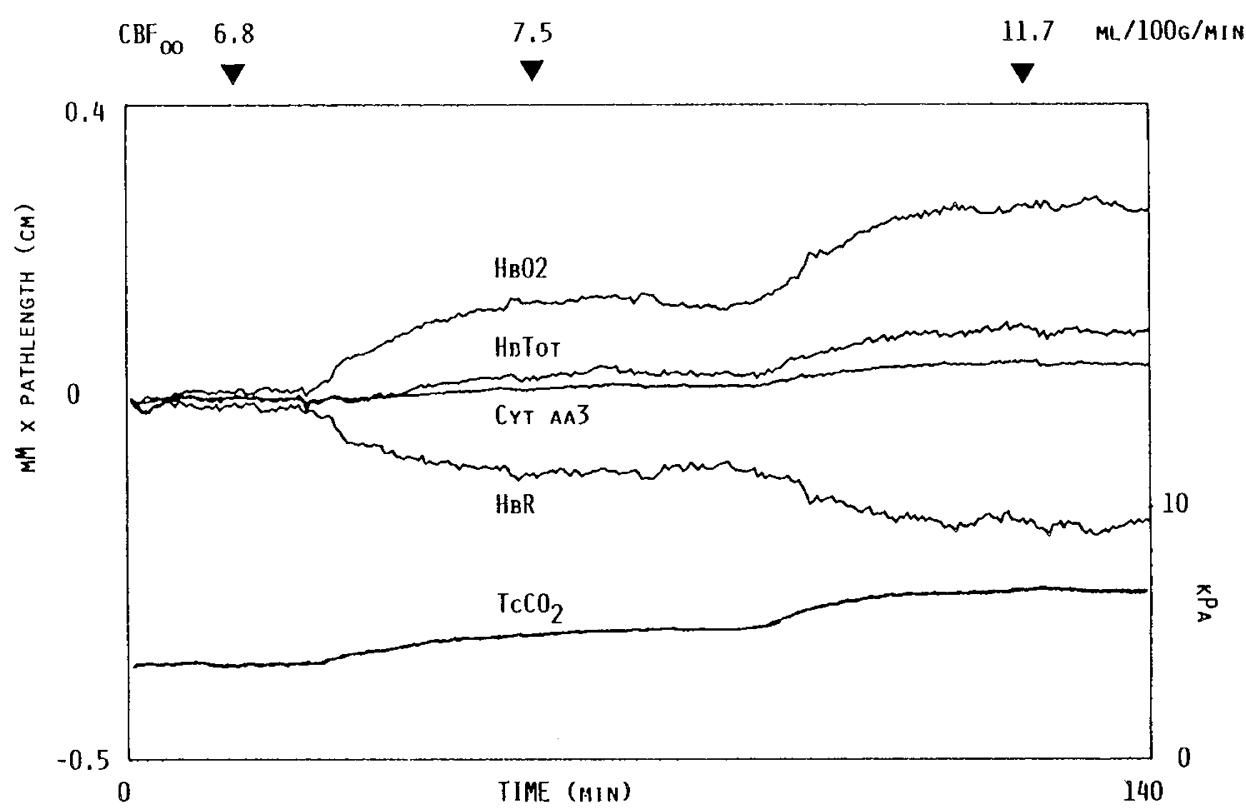

Fig. 1. Changes in relative concentrations ( $\mathrm{mM} \times$ path length) of HbTOT, $\mathrm{HbO}_{2}, \mathrm{HbR}$, and oxidized cytochrome aa 3 (Cyt aa3) vs changes in transcutaneous $\mathrm{CO}_{2}$ tension $\left(\mathrm{TCCO}_{2}\right)$ in a representative newborn infant. $\mathrm{CBF}_{\infty}$ was measured three times during the 140 -min period. 


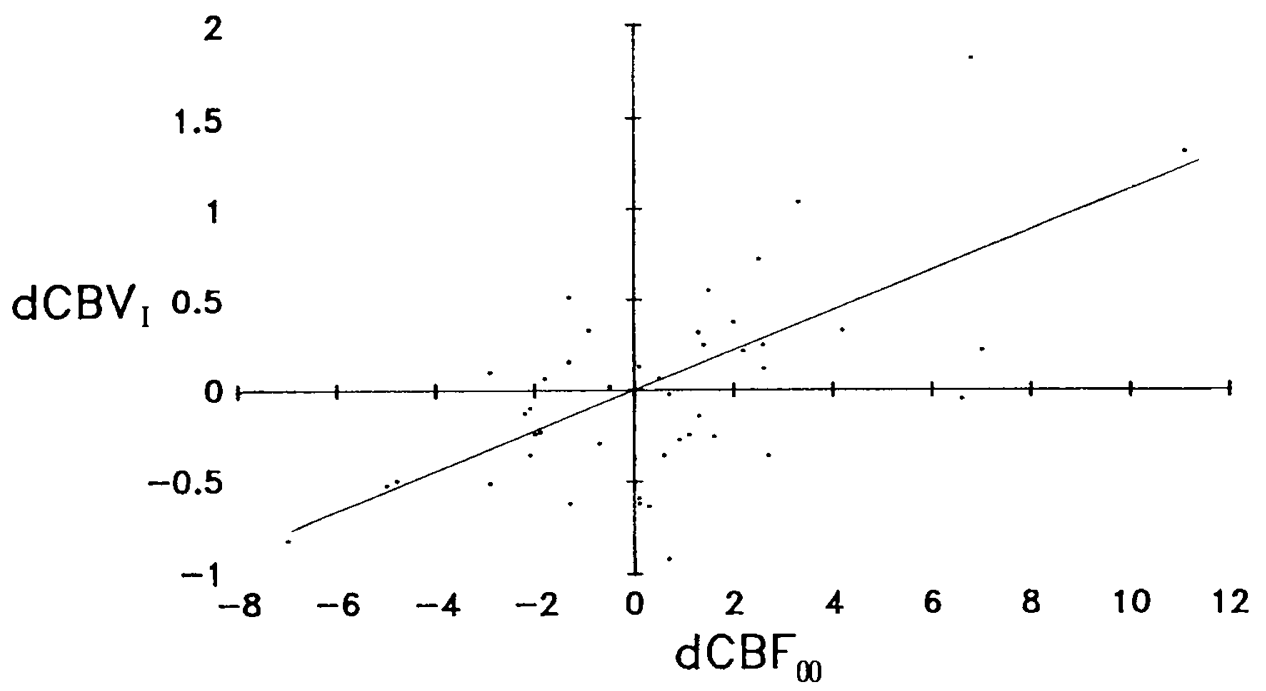

Fig. 2. Changes in $\mathrm{CBV}_{\mathrm{l}}\left(\mathrm{dCBV}_{\mathrm{s}} \mathrm{mL} / 100 \mathrm{~g} \times \mathrm{cm}\right)$ vs changes in $\mathrm{CBF}(\mathrm{dCBF} \infty \mathrm{mL} / 100 \mathrm{~g} / \mathrm{min})$ in 24 preterm infants. In each infant, three measurements were performed and the second measurement forced through $(0,0)$.

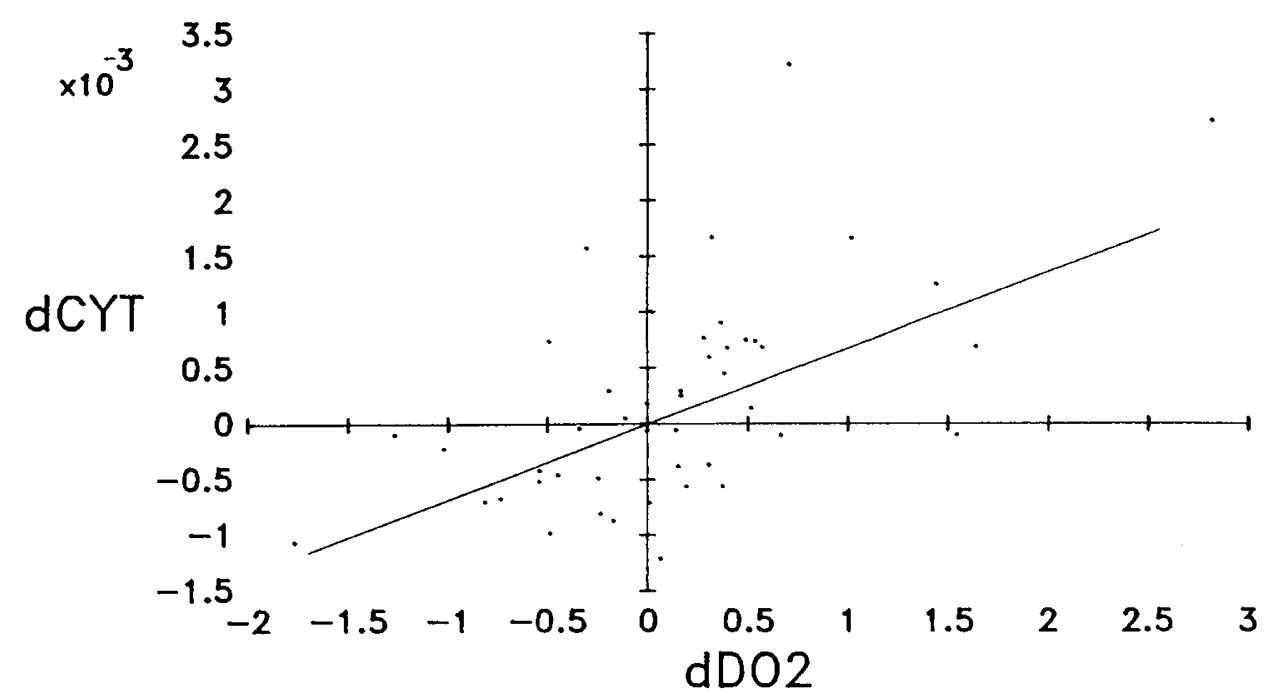

Fig. 3. Changes in oxidized cytochrome $\mathrm{aa}_{3}(\mathrm{dCyt} \mathrm{mM} \times \mathrm{cm})$ vs changes in oxygen delivery to the brain $(\mathrm{dDO} / \mathrm{mL} / 100 \mathrm{~g} / \mathrm{min})$ in $24 \mathrm{preterm}$ infants. In each infant, three measurements were performed and the second measurement forced through $(0,0)$.

maintenance $5 \mathrm{mg} / \mathrm{kg} / \mathrm{d})$ and paralyzed with pancuronium $(0.1$ $\mathrm{mg} / \mathrm{kg})$.

Design. The NIRS optodes were fixed on each side of the infant's head in the frontoparietal region closest to the scintillator. Transillumination mode with the optodes placed symmetrically and pointing toward each other at $180^{\circ}$ was attempted, but in some infants with large heads, the optodes had to be closer to obtain an acceptable signal to noise ratio; the optodes were therefore angled at 180 to $150^{\circ}$. The interoptode distance ranged from 5 to $7 \mathrm{~cm}$ (not included in the calculations).

When the infant had been undisturbed for about $30 \mathrm{~min}$, the CBF was measured while the NIRS signal was displayed and the data stored for later analysis. During the CBF measurement, MABP was recorded from an umbilical catheter and arterial blood drawn for measuring blood gases, $\mathrm{HbC}$, and $\mathrm{SaO}_{2}(\mathrm{ABL}$ and OSM2, Radiometer). After the measurement, ventilator settings (expiratory time) were adjusted to increase or decrease $\mathrm{PaCO}_{2}$ by $\pm 1.0 \mathrm{kPa}$, estimated from transcutaneous $\mathrm{PO}_{2}$ and $\mathrm{PCO}_{2}$ electrodes (TCM3, Radiometer), and a new steady state awaited before another measurement was taken. Values of $\mathrm{PaCO}_{2}$ from 3 to $5 \mathrm{kPa}$ were attempted as we recommended. If $\mathrm{PaO}_{2}$ was out of range $(8-10 \mathrm{kPa})$, the inspiratory fraction of oxygen was adjusted appropriately. The procedure was repeated, result- ing in three sets of data from each infant, obtained within about $2 \mathrm{~h}$. The infants were not disturbed during the investigation, and because of muscle paralysis, movement artifacts were avoided.

After the study, mean values of changes in OD at each wavelength, $\mathrm{HbTOT}, \mathrm{HbO}_{2}$, and $\mathrm{HbR}$, and oxidized cytochrome $\mathrm{aa}_{3}$ were calculated for the $15 \mathrm{~min}$ period over which $\mathrm{CBF}_{\infty}$ was measured. An estimate of changes in $\mathrm{CBV}_{\mathrm{I}}$ was calculated:

$100 / 1.05 \times($ change in HbTOT) $/ \mathrm{HbC} / 0.69(\mathrm{~mL} / 100 \mathrm{~g} \times \mathrm{cm})$

where 1.05 is the brain sp gr and 0.69 is the cerebral to large vessel hematocrit ratio (14). The relation between $C B V$ and $\mathrm{CBV}_{\mathrm{I}}$ is $\mathrm{CBV}=\mathrm{CBV}_{\mathrm{I}} /$ path length.

Oxygen delivery to the brain was calculated from the sum of physically dissolved and $\mathrm{Hb}-$ bound $\mathrm{O}_{2}$ :

$$
\begin{aligned}
\left(\left(\mathrm{PaO}_{2} \times 0.227+\mathrm{SaO}_{2} \times 84.0\right.\right. & \times \mathrm{HbC}) / 1000) \\
& \times \mathrm{CBF}_{\infty}\left(\mathrm{mL} \mathrm{O}_{2} / 100 \mathrm{~g} / \mathrm{min}\right) .
\end{aligned}
$$

Statistics. First, changes in OD for each wavelength, changes in $\mathrm{CBV}_{\mathrm{I}}$, and changes in $\mathrm{CBF}_{\infty}$ were used as dependent variables introducing $\mathrm{PaCO}_{2}, \mathrm{MABP}$, and $\mathrm{PaO}_{2}$ in a stepwise multiple regression analysis. A variable with 24 levels, one for each infant, 
was included (15) to analyze only the intraindividual variability. Next, the relation between changes in $\mathrm{OD}, \mathrm{CBV}_{\mathrm{I}}$, and $\mathrm{CBF}_{\infty}$ was analyzed. Finally, the association between changes in cytochrome $\mathrm{aa}_{3}$ and oxygen delivery was tested.

The Statistical Package for the Social Sciences (Chicago, IL) was used. The study was approved by the Ethics Committee for Greater Copenhagen and parental informed consent obtained for each infant.

\section{RESULTS}

$\mathrm{CBF}_{\infty}$ averaged $10.1 \mathrm{~mL} / 100 \mathrm{~g} / \mathrm{min}(\mathrm{SD} 4.0$ ) for all the measurements. Mean values of $\mathrm{PaCO}_{2}, \mathrm{MABP}$, and $\mathrm{pH}$ were $4.4 \mathrm{kPa}$ (SD 1.2), $39.4 \mathrm{~mm} \mathrm{Hg}$ (SD 8.3), and 7.43 (SD 0.09). Mean changes in $\mathrm{PaCO}_{2}, \mathrm{MABP}$, and $\mathrm{pH}$ between the serial measurements were $1.2 \mathrm{kPa}$ (SD 0.7), $3.2 \mathrm{~mm} \mathrm{Hg}$ (SD 2.2), and 0.07 (SD 0.04 ), respectively. $\mathrm{SaO}_{2}$ ranged between 0.90 and 1.0 (median $0.95)$.

Changes in $\mathrm{OD}$ versus changes in $\mathrm{PaCO}_{2}$ and $\mathrm{CBF} F_{\infty}$. Carbon dioxide-induced increase in $\mathrm{CBF}_{\infty}$ was correlated with increases in OD at 904, 845, 805, and 775 (Table 1). When $\mathrm{PaCO}_{2}$ was introduced in a bivariate regression analysis, changes in $\mathrm{CBF}_{\infty}$ reached a closer relationship to changes in OD than did changes in $\mathrm{PaCO}_{2}(p=0.0067$ and $p=0.023$, respectively). Probably, this finding was due to heterogeneity of $\mathrm{CBV}_{\mathrm{l}} / \mathrm{CBF}-\mathrm{CO}_{2}$ reactivity among the infants (see below).

Changes in $C B V_{I}$ versus changes in $\mathrm{PaCO}_{2}, \mathrm{MABP}$, and $\mathrm{PaO}_{2}$. Changes in $\mathrm{CBV}_{\mathrm{I}}$ were closely related to changes in $\mathrm{PaCO}_{2}(p<$ 0.0001 ), whereas neither changes in $\mathrm{MABP}$ nor $\mathrm{PaO}_{2}$ reached a significant relationship. In this study, $39.0 \%$ of the intraindividual variation of $C B V_{I}$ was accounted for by changes in $\mathrm{PaCO}_{2}$. Thus, $\mathrm{CBV}_{\mathrm{I}}$ increased by a mean of $1.70 \mathrm{~mL} / 100 \mathrm{~g} \times \mathrm{cm}(95 \%$ $\mathrm{CI} 1.05$ to 2.35$)$ per $\mathrm{kPa}$ increase in $\mathrm{PaCO}_{2}$. The $\mathrm{CBV}_{\mathrm{I}}-\mathrm{O}_{2}$ reactivity was calculated to $-0.16 \mathrm{~mL} / 100 \mathrm{~g} \times \mathrm{cm}$ per $\mathrm{kPa}(95 \%$ $\mathrm{CI}-0.43$ to 0.10 ) and the $\mathrm{CBV}_{\mathrm{I}}-\mathrm{MABP}$ reactivity to $0.05 \mathrm{~mL} /$ $100 \mathrm{~g} \times \mathrm{cm}$ per $\mathrm{mm} \mathrm{Hg}(95 \% \mathrm{CI}-0.27$ to 0.37$)$. In infants investigated during the second day of life, the $\mathrm{CBV}_{\mathrm{r}}-\mathrm{CO}_{2}$ reactivity was $42.0 \%$ higher than in infants investigated during the first day of life, but this difference was not significant (Table 2).

The $\mathrm{PaCO}_{2}$-induced changes in $\mathrm{CBV}_{\mathrm{I}}$ were due to changes in $\mathrm{HbO}_{2}$, whereas $\mathrm{HbR}$ tended to decrease with increasing $\mathrm{PaCO}_{2}$ (Fig. 1).

Changes in $C B F_{\infty}$ versus changes in $\mathrm{PaCO}_{2}, M A B P$, and $\mathrm{PaO}_{2}$. The relationship between changes in the three variables and $\mathrm{CBF}_{\infty}$ was similar to that of $\mathrm{CBV}_{\mathrm{I}}$; here, $52.6 \%$ of the intraindividual variation of $\mathrm{CBV}_{\infty}$ was explained by changes in $\mathrm{PaCO}_{2}(p$ $<0.0001$ ). In addition, a significant difference in $\mathrm{CBF}_{\infty}-\mathrm{CO}_{2}$ reactivity was found between infants of different ages. Thus, the mean $\mathrm{PaCO}_{2}$ reactivity was $11.9 \%$ per $\mathrm{kPa}$ during the first day of life and $27.3 \%$ per $\mathrm{kPa}$ during the second day (Table 2). Changes in $\mathrm{PaO}_{2}$ and $\mathrm{MABP}$ were not significantly related to changes in $\mathrm{CBF}_{\infty}$ ( $p=0.45$ and $p<0.93$, respectively).

Changes in $C B V_{I}$ versus changes in $C B V_{\infty}$. A linear relation was found between changes in $\mathrm{CBF}_{\infty}$ and changes in $\mathrm{CBV}_{\mathrm{I}}(r=$ $0.70 ; p<0.0001 ;$ Fig. 2). Thus, $\mathrm{CBV}_{\mathrm{I}}$ changed by a mean of 0.63 $\mathrm{mL} / 100 \mathrm{~g} \times \mathrm{cm}$ per $\mathrm{mL} / 100 \mathrm{~g} / \mathrm{min}$ change in $\mathrm{CBF}_{\infty}(95 \% \mathrm{CI}$ 0.40 to 0.87 ).

Changes in oxidized cytochrome a $a_{3}$ versus oxygen delivery. The oxygenation level of cytochrome $\mathrm{aa}_{3}$ increased linearly with increases in oxygen delivery $(r=0.72 ; p<0.0001)$ as presented in Fig. 3. The regression coefficient was calculated:

$0.0038 \mathrm{mM}$

$\times \mathrm{cm}$ per $\mathrm{mL} / 100 \mathrm{~g} / \mathrm{min}(95 \% \mathrm{Cl} 0.0020$ to 0.0056$)$.

This relationship, however, disappeared when $\mathrm{HbO}_{2}$ was introduced as a second variable in the statistical analysis, indicating that the estimates of oxidized cytochrome $\mathrm{aa}_{3}$ and $\mathrm{HbO}_{2}$ were strongly correlated to each other.

\section{DISCUSSION}

In our study, the OD at all four wavelengths increased significantly when $\mathrm{CBF}_{\infty}$ rose at higher $\mathrm{PaCO}_{2}$ levels. This finding is consistent with increasing amounts of absorbants in the brain. The magnitude of each regression coefficient, the lowest observed for $775 \mathrm{~nm}$, indicates that arteriolar dilation occurred, resulting in a higher mean $\mathrm{Hb}$ saturation.

Conversion of the recordings to an index of $\mathrm{CBV}$ gave a linear relation between changes in $\mathrm{CBV}_{\Upsilon}$ and $\mathrm{CBF}_{\infty}$ within the observed range of $\mathrm{PaCO}_{2}(2.1$ to $7.8 \mathrm{kPa})$, but the changes in $\mathrm{CBV}_{\mathrm{I}}$ did not ascertain an age-dependent difference in the $\mathrm{PaCO}_{2}$ reactivity. An attenuated $\mathrm{CO}_{2}$ reactivity in mechanically ventilated preterm infants during the first day of life has recently been observed $(16,17)$.

It should be noted that the $\mathrm{CBV}_{\mathrm{I}}-\mathrm{CBV}_{\infty}$ relationship reported in this study may only be valid for $\mathrm{PaCO}_{2}$-induced changes. $\mathrm{CBF}$ is determined by MABP, intracranial pressure, blood viscosity, and the diameter of arteries and arterioles. However, CBV is mainly determined by the diameter of venules and arterioles, the latter thus being a common denominator for both CBF and $\mathrm{CBV}$. Changes in the cerebral perfusion pressure may give a different relationship, as may conditions involving changes in the central venous pressure and cerebral venous drainage.

Although changes in $\mathrm{CBV}_{\mathrm{I}}$ were closely related to changes in $\mathrm{CBF}_{\infty}$, the data have certain limitations. Quantification of the NIRS recordings to absolute concentrations and CBF presupposes that the light path length is known. However, determination of the path length is not straightforward because of multiple scatterings of light inside the head (18). The scattering effect depends on several factors, e.g. cell concentration, myelination, and bone mineralization, implying that the path length is a complex function of the geometrical distance between the optodes (according to the Lambert-Beer law), the amount of scattering elements (gestational age), and the concentration of chromophores. Furthermore, the path length is different for the various wavelengths used (775-904 nm), with a longer path length at shorter wavelengths; this should be taken into account when quantification is attempted. Hopefully, these problems will be clarified in the future. In our study, we attempted to keep the interoptode distance within a narrow range, but our knowledge of the light path length may have optimized the relation between changes in $\mathrm{CBV}_{1}$ and $\mathrm{CBF}_{\infty}$.

The oxygenation level of cytochrome $\mathrm{aa}_{3}$ correlated with the oxygen delivered to the brain. Inasmuch as changes in oxidized cytochrome $\mathrm{aa}_{3}, \mathrm{HbO}_{2}$ and oxygen delivery were expected to be highly correlated in the present experimental design, the statistical analysis cannot be conclusive with regard to presence of cross-talk between oxidized cytochrome and oxygenated $\mathrm{HbO}_{2}$ respectively. Three important considerations should be made. First, if $\mathrm{HbO}_{2}$ and oxidized cytochrome $\mathrm{aa}_{3}$ change in parallel, it means that cytochrome $\mathrm{aa}_{3}$ is partly reduced at normal $\mathrm{PaO}_{2}$ tensions as previously suggested $(19,20)$. These studies, however, used the same technique, with the same probability that apparent cytochrome $\mathrm{aa}_{3}$ redox changes are artifactual. Second, the present algorithm for calculating changes in cytochrome $a_{3}$ is derived from studies of rat brain exchange transfused with fluorocarbon and may therefore be affected by "noise" due to $\mathrm{pH}$ transients (which may affect the absorption spectra), fluctuation in scattering (vasodilation during hypoxia), or residual $\mathrm{Hb}$ after fluorocarbon exchange. Further in vitro and animal studies elaborating these problems are needed. Finally, and perhaps most importantly, the amount of cytochrome $\mathrm{aa}_{3}$ may be very small in the preterm brain, as the low cerebral activity in preterm neonates implies a low energy requirement for electrical transmission (21). Consequently, fluctuations in redox level of cytochrome $\mathrm{aa}_{3}$ may be easily masked.

In conclusion, $\mathrm{PaCO}_{2}$-induced changes in $\mathrm{CBF}_{\infty}$ resulted in parallel changes in $\mathrm{CBV}_{1}$, presumably due to arteriolar dilation of the cerebral vessels. Similarly, increase in oxygen delivery to 
the brain was accompanied by increase in the signal of oxidized cytochrome $a a_{3}$, but there are reasons to believe this to be artifactual.

Acknowledgments. The Gerda and Åge Haench Foundation and the Dagmar Marschal Foundation gave financial support. The statistical method was provided by the Statistical Research Unit, University of Copenhagen, Copenhagen, Denmark.

\section{REFERENCES}

1. Jöbsis FF 1977 Noninvasive infrared monitoring of cerebral and myocardial oxygen sufficiency and circulatory parameters. Science 198:1264-1267

2. Brazy JE, Darrel VL, Mitnick MH, Jöbsis FF 1985 Noninvasive monitoring of cerebral oxygenation in preterm infants: preliminary observations. Pediatrics 75:217-225

3. Wyatt JS, Cope M. Delpy DT, Wray S, Reynolds EOR 1986 Quantification of cerebral oxygenation and haemodynamics in sick new born infants by near infrared spectrophotometry. Lancet 8515:1063-1066

4. Risberg J, Ancri D, Ingvar DH 1969 Correlation between cerebral blood volume and cerebral blood flow in the cat. Exp Brain Res 8:321-326

5. Smith AL, Neufeld GR, Ominsky AJ, Wollman $\mathrm{H} 1971$ Effect of arterial $\mathrm{CO}_{2}$ tension on cerebral blood volume, mean transit time, and vascular volume. J Appl Physiol 31:701-707

6. Phelps ME, Grubb RL, Ter-Pogossian MM 1973 Correlation between $\mathrm{PaCO}_{2}$ and regional cerebral blood volume by $\mathrm{x}$-ray fluorescence. J Appl Physiol 35:274-280

7. Takashima S, Ando Y 1988 Reflectance spectrophotometry, cerebral blood flow and congestion in young rabbit brain. Brain Dev 10:20-23

8. Greenberg JH, Alavi A, Reivich M, Kuhl D, Uzzell B 1978 Local cerebral blood volume response to carbon dioxide in man. Circ Res 43:324-33

9. Lassen NA 1974 Control of cerebral circulation in health and disease. Circ Res 34:749-760
10. Wray S, Cope M. Delpy DT, Wyatt JS, Reynolds EOR 1988 Characterization of the near infrared absorption spectra of cytochrome $\mathrm{aa}_{3}$ and haemoglobin for the non-invasive monitoring of cerebral oxygenation. Biochim Biophys Acta 933:184-192

11. Greisen G Pryds O 1988 Intravenous ${ }^{133} \mathrm{Xe}$ clearance in preterm neonates with respiratory distress. Internal validation of $\mathrm{CBF}_{\infty}$ as a measure of global cerebral blood flow. Scand J Clin Lab Invest 48:673-678

12. Obrist W, Thompson HK, Wang HS, Wilkinson WE 1975 Regional cerebral blood flow estimated by ${ }^{133}$ Xenon inhalation. Stroke 6:245-256

13. Greisen G 1986 Cerebral blood flow in preterm infants during the first week of life. Acta Paediatr Scand 75:43-51

14. Lammertsma AA, Brooks DJ, Beany RP, Turton DR, Kenset MJ, Heather JD, Marshall J, Jones T 1984 In vivo measurements of regional cerebral haematocrit using positron emission tomography. J Cereb Blood Flow Metab $4: 317-322$

15. Smith EO 1987 Analysis of repeated measures designs (editorial). J Pediatrics 111:723-725

16. Levene M, Shortland D, Gibson N, Evans DH 1988 Carbon dioxide reactivity of the cerebral circulation in extremely premature infants: effects of postnatal age and indomethacin. Pediatr Res 24:175-179

17. Pryds O, Greisen G, Lou H, Friis-Hansen B 1989 Heterogeneity of cerebral blood flow in mechanically ventilated, preterm infants. J Pediatr 115:638645

18. Delpy DT, Cope M, van der Zee P, Wray S, Wyatt JT 1988 Estimation of optical pathlength through tissue from direct time of flight measurement. Phys Med Biol 33:1433-1442

19. Piantadosi CA, Hemstreet TM, Jöbsis-Vandervliet FF 1986 Near-infrared spectrophotometric monitoring of oxygen distribution to intact brain and skeletal muscle tissues. Crit Care Med 14:698-706

20. Thorniley MS, Wickramasinghe YABD, Rolfe P 1988 Near infra-red spectroscopy: a new technique for the non-invasive monitoring of tissue and blood oxygenation in vivo. Biochem Soc Trans 16:978-979

21. Astrup J 1982 Energy-requiring cell functions in the ischaemic brain. J Neurosurg 56:482-497 